\title{
CORROSION AND TARNISHING CHARACTERISTICS OF LOW GOLD CONTENT DENTAL CASTING ALLOYS
}

\author{
Kenneth J. Fioravanti * \& Randall M. German** \\ * Applied Research \& Development, Air Products \& Chemicals, Allentown, PA 18195, USA \\ ** Materials Engineering Department, Rensselaer Polytechnic Institute, Troy, NY 12180-3590
}

\begin{abstract}
Quantitative measurements of tarnishing and corrosion resistance in low gold content dental casting alloys in a variety of metallurgical states have shown that the desirable features of such alloys are a large grain size, a minimum of segregation, and the absence of precipitates and ordered phases.
\end{abstract}

\section{Introduction}

The chemical stability of dental casting alloys has long been a matter of concern to dentists because of the negative consequences of tarnish and corrosion [1-5]. In the past, the use of high-nobility alloys (those with a high content of gold or other noble metals) generally ensured resistance to attack in the human mouth. However, during the past decade the use of low-nobility alloys has become widespread due to economic pressures. As a consequence of this trend, problems with the chemical stability of these alloys have emerged. Accordingly, the dental materials science community has begun to pay more attention to the quantification of the chemical stability of dental alloys in terms of their tarnish and corrosion behaviour [1-22]. This process has required refinements in several key areas, including identification of appropriate tests, acceptance of quantification procedures, isolation of nobility effects and, most recently, identification of effects arising from microstructural changes. It is this latter topic which is the main concern of our study.

The microstructure of low gold content alloys can be manipulated through heat treatments. For example, grain size can be altered by varying the solidification rate and by post-solidification anneals. The degree of segregation in a casting likewise depends on homogenization anneals, alloy composition, and casting conditions. Furthermore, the low-gold alloys in particular exhibit both precipitation and ordering reactions which affect chemical stability.

In prior experiments, we have made progress in the identification of in vitro test procedures for evaluating the performance of dental casting alloys $[4,8,9,21,22]$. These tests have been applied to a variety of gold [23] and palladium-silver alloys [24] with good success. The studies have provided the desired information on the effects of alloy composition, although it has become evident that heat treatment and microstructure are also important parallel parameters. Indeed, in some cases the role of microstructural effects is as large as that of nobility $[8,18$, 23]. A specific study was therefore undertaken to clarify the influence of microstructure on chemical stability.

For our examination we elected to hold nobility (gold content) fairly constant while adjusting the silver/copper ratio. In order to provide basic information on the significance of the silver/copper ratio, five ternary (gold -silver-copper) alloys with 35 atomic per cent gold were prepared. Three commercial low-gold dental alloys were also included in the study for comparison. The adjustments to microstructure were attained using various heat treatments and solidification rates. Thus, the test matrix for the 
investigation consisted of eight alloys and five thermal conditions, namely as-cast, rapidly solidified, homogenized, ordered and aged.

The microstructures of the alloys after the different thermal treatments were established by optical and electron microscopy, while their chemical stabilities were evaluated using spectrophotometrically measured color changes (for tarnish) and potentiodynamic polarization curves (for corrosion). Because of the size of the test matrix, not all combinations of alloys and thermal treatments could be examined.

\section{Experimental}

The compositions of the eight low-gold alloys tested are given in Table I. Miracast*, Sunrise** and Tiffany** are commercially available and contain as many as six elements. The ternary laboratory-prepared alloys were formulated such that a constant noble metal content (gold + platinum + palladium) of 35 atomic per cent was maintained. Hence only the gold/silver ratio varied in these materials. The nobility in the set of commercial alloys varied from 25 atomic per cent (Miracast) to 36 atomic per cent (Tiffany).

All materials were initially cast into $10 \times 10 \times 2 \mathrm{~mm}$ paddles using the lost-wax process, which is the standard method for producing crown and bridge restorations. Subsequent thermal processing of the as-cast paddles included homogenization, ordering and aging. Each of these heat treatments was performed under an argon atmosphere in

* product of J.M. Ney Co., Bloomfield, CT

** product of Sterngold Corp., Stamford, CT a horizontal tube furnace. All samples were waterquenched from their respective aging temperatures.

Homogenization, which was done at $800^{\circ} \mathrm{C}$ over 12 hours, eliminated most or all of the casting segregation [21]. Ordering was carried out for 20 minutes at $350^{\circ} \mathrm{C}$ and designed to promote the formation of the $\mathrm{Au}-\mathrm{Cu}$ ordered phase. Aging of the alloys was accomplished with a 40 -hour soak at $350^{\circ} \mathrm{C}$. This treatment was performed as a check of the completeness of ordering and also of the tendency of the material to revert to a dual-phase microstructure.

In addition to the abovementioned treatments, samples of several of the test alloys were produced by a rapid solidification rate (RSR) technique in order to minimize microstructural inhomogeneities which are generally found in alloys produced using conventional casting methods. Due to the limited quantities of material available, the ternary alloys I, III and V were not processed by RSR. Also, rapid solidification of Miracast was not possible because the crucible nozzle quickly clogged with $\mathrm{ZnO}$, which formed as a result of the preferential oxidation of zinc.

After each of the heat treatments, microhardness measurements were made and optical micrographs were taken. Some samples were examined further using scanning electron microscopy (SEM) and transmission electron microscopy (TEM). TEM specimen preparation was performed in accordance with the procedures outlined by Prasad, et al. [25].

\section{Measurement of tarnish and corrosion}

The tarnish and corrosion performance of the alloy set in the various metallurgical states was assessed using the test battery developed by Treacy and German [4]. The degree of tarnish was quantified by daily spectrophotometric

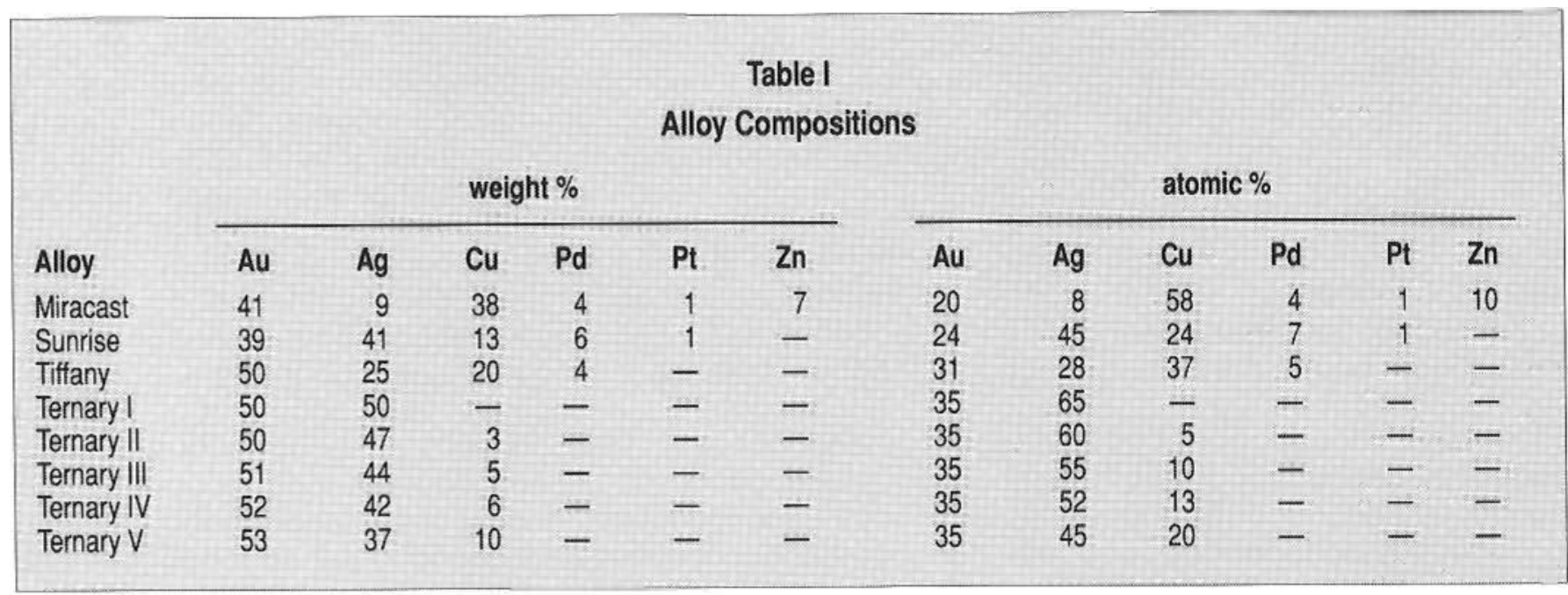




\section{Rapid Solidification Rate (RSR) Processing}

Rapid solidification or quenching of alloys has several important consequences, which include grain refinement, extension of solid solubility and reduced microsegregation. Several advanced materials, such as intermetallic or 'glassy' metals, are produced commercially with RSR techniques.

Several methods are available for RSR processing. In our tests with low gold content dental casting alloys, we used a twin-roll, rapid solidification apparatus (illustrated), which is capable of cooling rates up to $1000000^{\circ} \mathrm{C} / \mathrm{s}$ and normally produces RSR material in the form of 0.1 to $0.2 \mathrm{~mm}$ thick ribbons. In conventional melt-spinning RSR practice, the metallic ribbons produced often exhibit differential cold-face and hot-face microstructures $[32,33]$, caused by cooling rate differences through the thickness of the strip. The side of the ribbon in contact with the wheel (cold face) solidifies faster than the outer face which can lead to a variety of microstructures across the strip thickness.

The RSR gold alloys produced with the twin-roll rapid quench apparatus did not exhibit significant microstructural differences when each side of the ribbon was examined. This is due to the elimination of the hot face by producing intimate contact with the rolls on both sides of the ribbon during solidification. Thus, more uniform cooling of the metal is produced with the twin-roll device.

The performance of the test alloys in the RSR condition was consistent with those of the other heat treatments, i.e., dual phase and/or small-grained materials are the least resistant materials. The RSR processing is somewhat unique and unconventional. Thus, this type of processing will probably not find application in most dental casting shops.

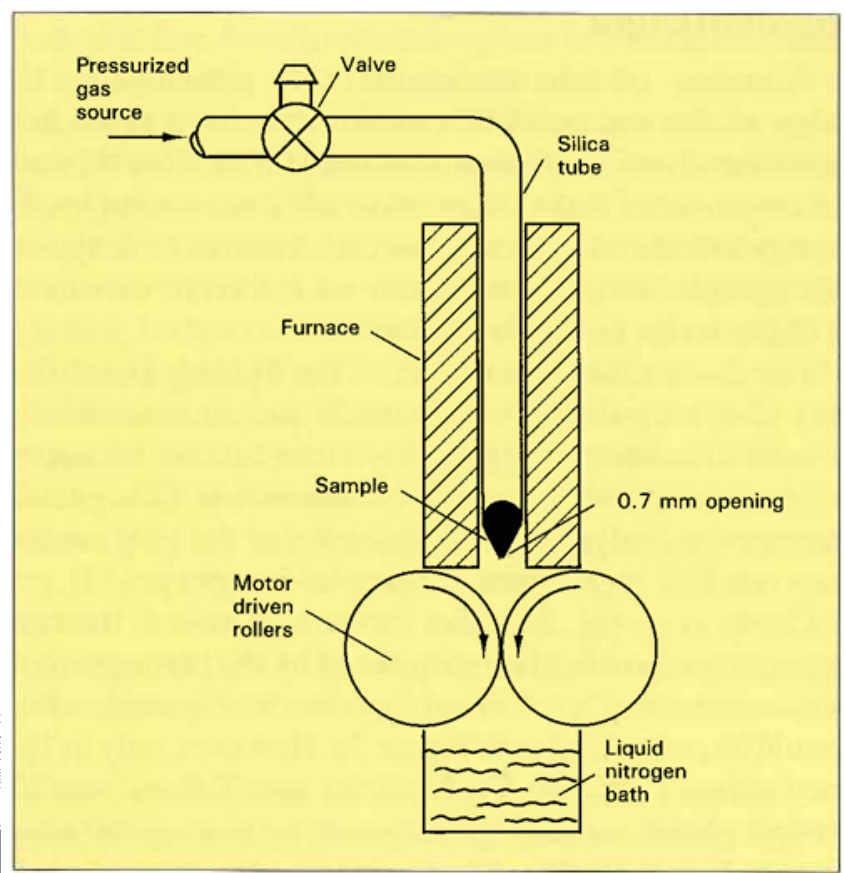

Schematic diagram of the twin-roller rapid quench apparatus measurements of surface color changes over a 72-hour period. The test solutions employed were 0.5 per cent sodium sulfide and a standard artificial saliva [4]. In all cases, the solution temperature was kept constant at $37^{\circ} \mathrm{C}$. The calculated color change, $\Delta \mathrm{E}^{*}$, is the vector connecting the three-dimensional color coordinates of the alloy surface before and after exposure to the test solution.

$\mathrm{A} \Delta \mathrm{E}^{*}$ value of 1.0 is barely discernible by the human eye, whereas color changes of 10 and above are easily recognized as surface (tarnish) discoloration. Thus, a quantitative ranking of tarnish resistance can be made using this technique [21]. The details concerning sample preparation and equipment specifications have been published elsewhere $[4,8,9,21]$.

Corrosion performance was determined by measuring current density during a potentiodynamic scan in the range from -1 to $+1 \mathrm{~V}$. The potential was measured on the standard calomel electrode (SCE) scale and was varied at a rate of $1 \mathrm{mV} / \mathrm{s}$. Test environments were deaerated 1 per cent $\mathrm{NaCl}$ and aerated artificial saliva [4, 22]. During the corrosion scan, solution temperature was maintained at $37^{\circ} \mathrm{C}$. The test samples were prepared using the procedure outlined in ASTM standard G5, using the apparatus described in detail elsewhere $[4,22]$.

The corrosion scan consisted of two main parts: the anodic or forward region and the cathodic or reverse regime. A schematic of the forward scan, -1 to $+1 \mathrm{~V}$ (SCE) is shown in Figure 1. Two quantitative corrosion parameters were determined for each sample from similar

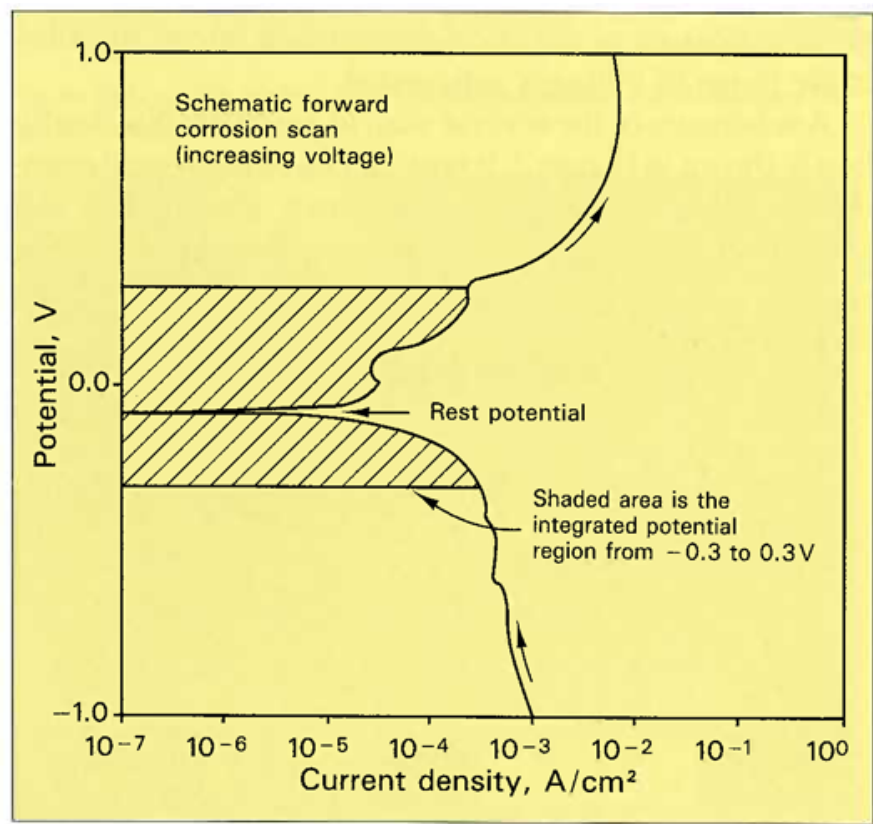

Fig. 1 Diagram showing the current density/voltage relationship during a forward corrosion scan, indicating the rest potential and forward integral (area from -0.3 to $+0.3 \mathrm{~V}$ ) 


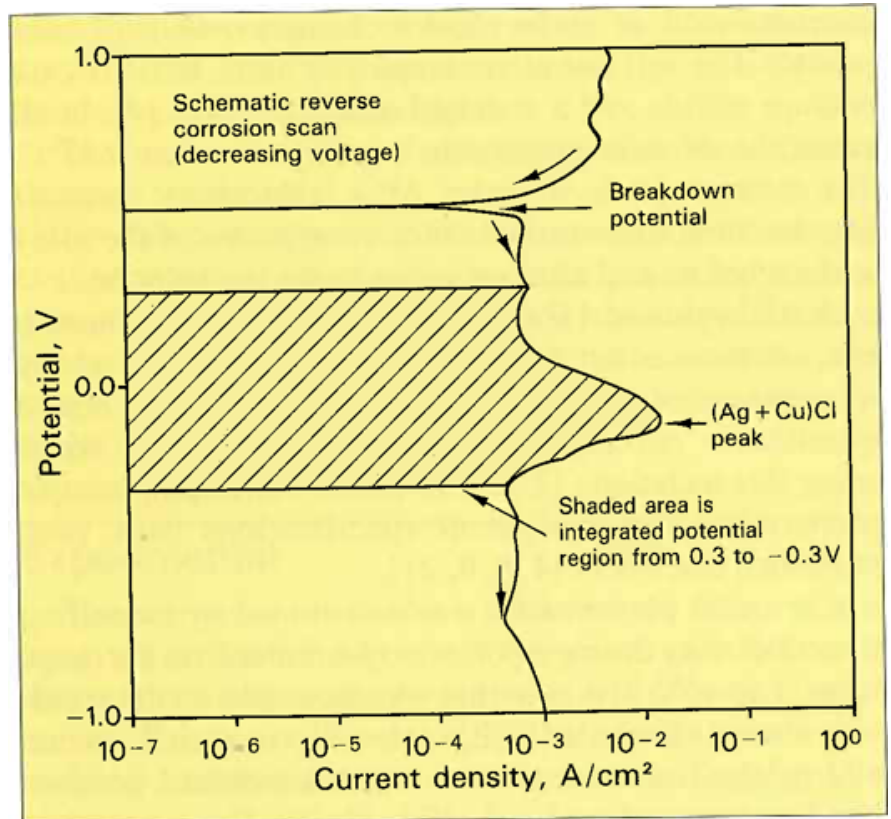

Fig. 2 The reverse corrosion scan illustrating the location of the breakdown potential, chloride corrosion peak, and reverse integral (area from +0.3 to $-0.3 \mathrm{~V}$ )

graphs. The rest potential is the point at which the sample current flow changes from cathodic to anodic. The crosshatched area under the curve is the forward integral. The integration limits, -0.3 to $+0.3 \mathrm{~V}$ (SCE), were chosen because they contain potentials most typically observed in the oral cavity [4]. The integrated potential parameter gives a measure of the average corrosion rate of the alloy in the range of voltages anticipated.

A schematic of the reverse scan in 1 per cent $\mathrm{NaCl}$ solution is shown in Figure 2. It provides three additional quantitative parameters. The breakdown potential is the

\begin{tabular}{|lcl|}
\hline \multicolumn{2}{c|}{$\begin{array}{c}\text { Table II } \\
\text { Ag:Cu Ratios of the Test Alloys }\end{array}$} \\
\hline & & \\
\hline Alloy & Ag:Cu & Compl. Homogen. \\
& Ratio & after 12 hr $/ 800^{\circ} \mathrm{C}$ \\
\hline Miracast & & \\
\hline Sunrise & 0.14 & yes \\
\hline Tiffany & 1.88 & no \\
Ternary I & 0.76 & yes \\
Ternary II & N.A. & yes \\
Ternary III & 12.00 & yes \\
Ternary IV & 5.50 & yes \\
Ternary V & 4.00 & yes \\
\hline
\end{tabular}

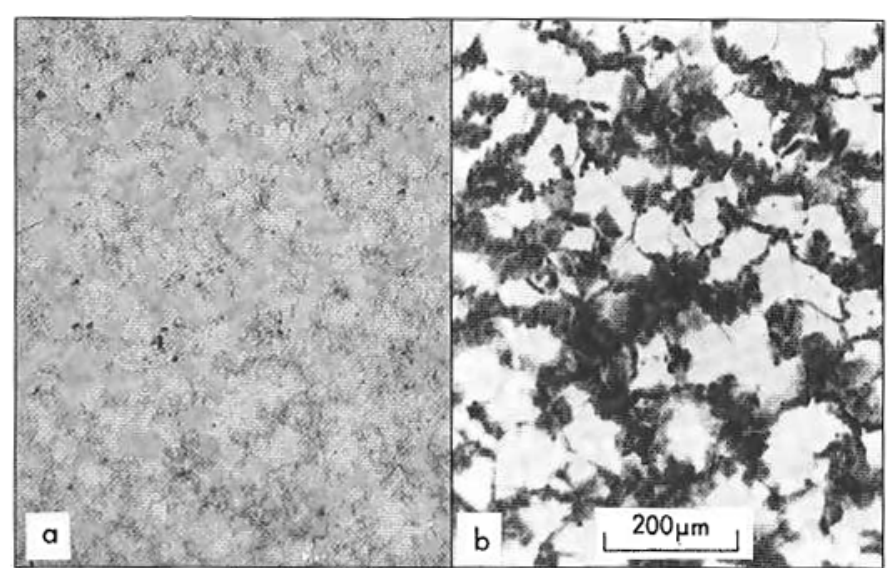

Fig. 3a (left) and 3b (right) Examples of the as-cast microstructure corresponding to (a) Ternary II, and (b) Tiffany

cathodic equivalent of the rest potential. The magnitude of the peak in the current density curve is associated with the amount of silver and copper chlorides formed. The height of the $(\mathrm{Ag}+\mathrm{Cu}) \mathrm{Cl}$ peak is an index of the corrodable species present on the alloy surface. The reverse integral is shown as a cross-hatched area and is calculated within the same limits as the forward integral. This, too, provides a measure of the average corrosion rate that might be encountered in the human mouth.

\section{Results and discussion}

\section{Microstructure}

A variety of microstructures were produced by the range of thermal processes used. Also, for a given heat treatment, there were microstructural differences between the commercial and ternary materials due to complex alloying effects in the commercial materials. A typical micrograph from each alloy sub-set is therefore included to characterize each heat treatment.

The as-cast microstructures of the Ternary II and Tiffany alloys are shown in Figures $3 a$ and $3 b$, respectively. In both micrographs, the darkly etched phase is copperrich and the lighter constituent is silver-rich. Quantitative microprobe analyses have indicated that the gold content does not vary significantly from phase to phase [26].

Corso, et al. $[21,22]$ have shown that most of the casting segregation could be eliminated by the homogenizing heat-treatment. This is clearly evident in Figure 4, which should be contrasted with Figure 3a. However, only in Ternary alloys I through IV, Miracast and Tiffany was the second phase completely removed by homogenization. Figures $5 \mathrm{a}$ and $5 \mathrm{~b}$ reveal that a portion of the second phase still remained in Ternary $\mathrm{V}$ and Sunrise after homogeniza- 


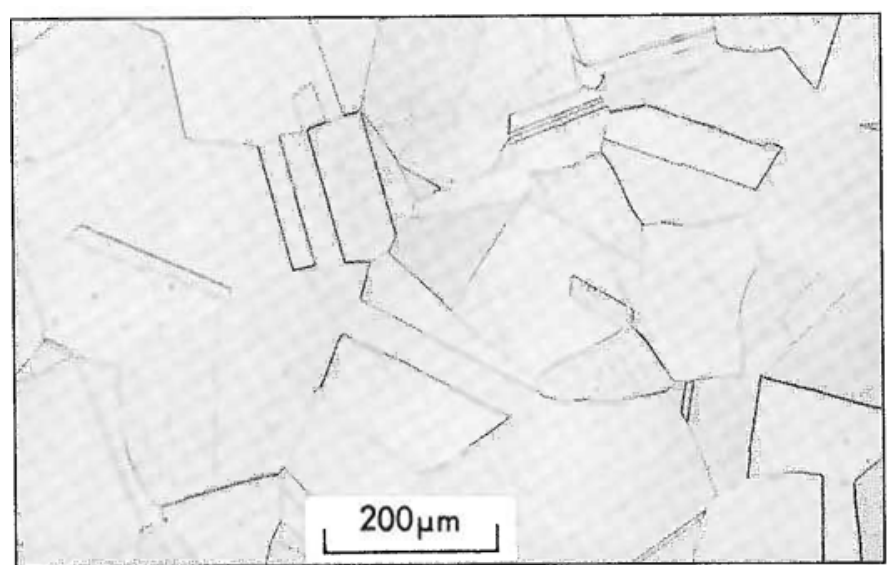

Fig. 4 An example of the microstructure of one of the alloys after homogenization, showing the single phase structure of Ternary II

tion. Previous investigations have suggested that the silver/copper atomic ratio was an important factor in assessing the tendency of a low gold content alloy to form and retain a copper-rich phase [26], The silver/copper ratios are listed in Table II. These data indicate that a ratio near 2.0 is the most favourable for retention of the second phase after homogenization.

Figures $6 \mathrm{a}$ and $6 \mathrm{~b}$ show micrographs of the Ternary III and Tiffany alloys in the ordered state. By comparing Figure 6 and Figure 4, it can be concluded that there are no apparent microstructural differences between the homogenized and ordered samples at low magnifications. However, the bright-field TEM image shown in Figure 7 reveals that fine $\mathrm{Au}-\mathrm{Cu}$ ordered regions formed in a sample of Tiffany. This ordered weave closely resembles micrographs published in other TEM studies of low-gold alloys [25, 27, 28]. Selected-area diffraction patterns of Tiffany before and after ordering showed a characteristic face-centered cubic (f.c.c.) structure. Ordering in the $\mathrm{Au}$ $\mathrm{Cu}$ system resulted in the formation of coherently nucleated, body-centered tetragonal (b.c.t.) platelets [25]. On ordering, $\{111\}$-type reflections, forbidden in f.c.c. alloys due to structure factor rules, were apparent in the electron diffraction patterns, giving additional evidence of ordering. Further examination revealed satellite reflections along $\{111\}$ which suggests that nucleation occurred along these planes. The lattice parameter of Tiffany was measured before and after ordering, giving values of $0.405 \mathrm{~nm}$ and $0.383 \mathrm{~nm}$, respectively. These results are also consistent with that of previously published work [26].

With the exception of Ternary I, which contained no copper, all materials showed resegregation of the copperrich and silver-rich phases after the 40-hour aging treatment. Figures $8 \mathrm{a}$ and $8 \mathrm{~b}$ indicate that the silver-rich phase

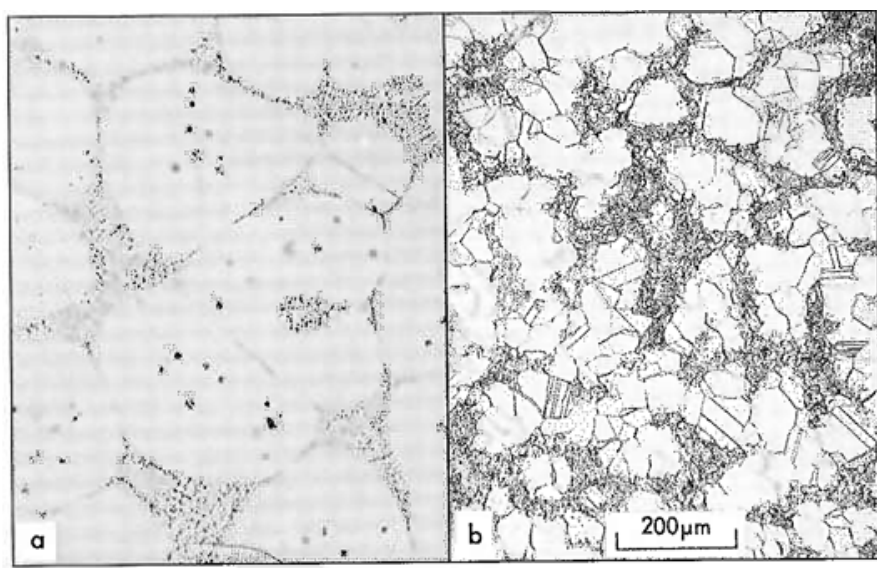

Fig. 5a (left) and 5b (right) Typical microstructures after the homogenization anneal where a second phase is still present; (a) Ternary $V$, and (b) Sunrise

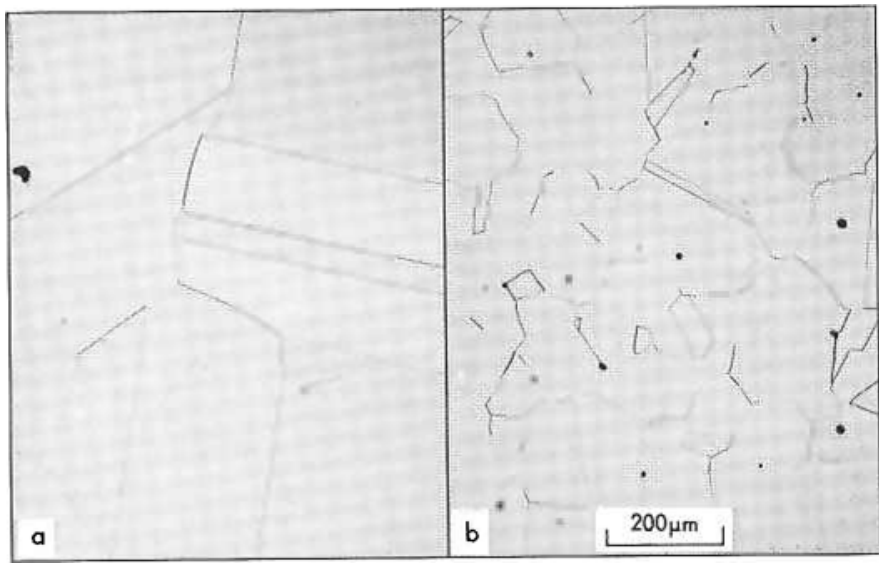

Fig. 6a (left) and 6b (right) Ordered microstructures for (a) Ternary III, and (b) Tiffany

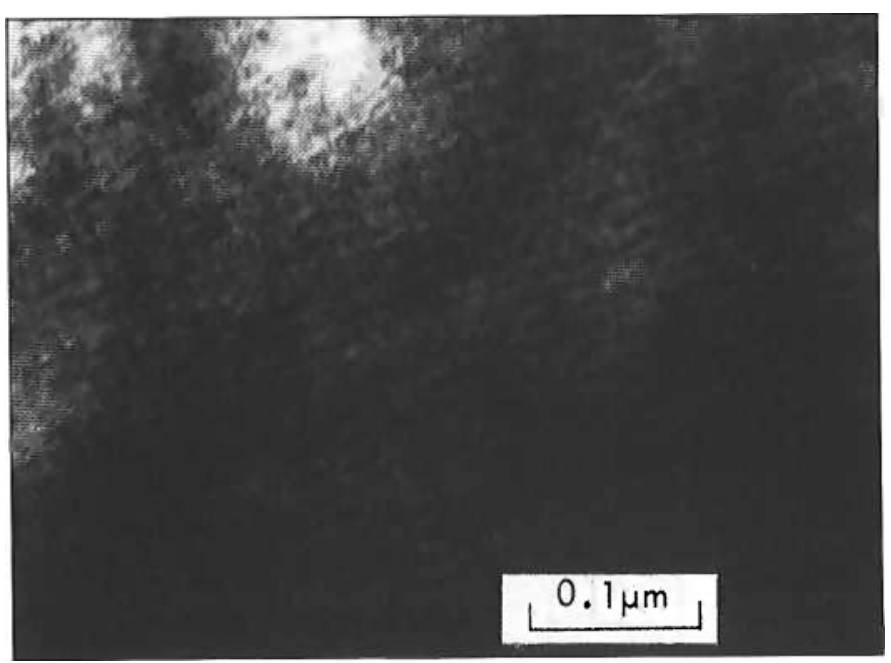

Fig. 7 Transmission electron micrograph of Tiffany in the ordered condition, showing a fine weave to the microstructure 


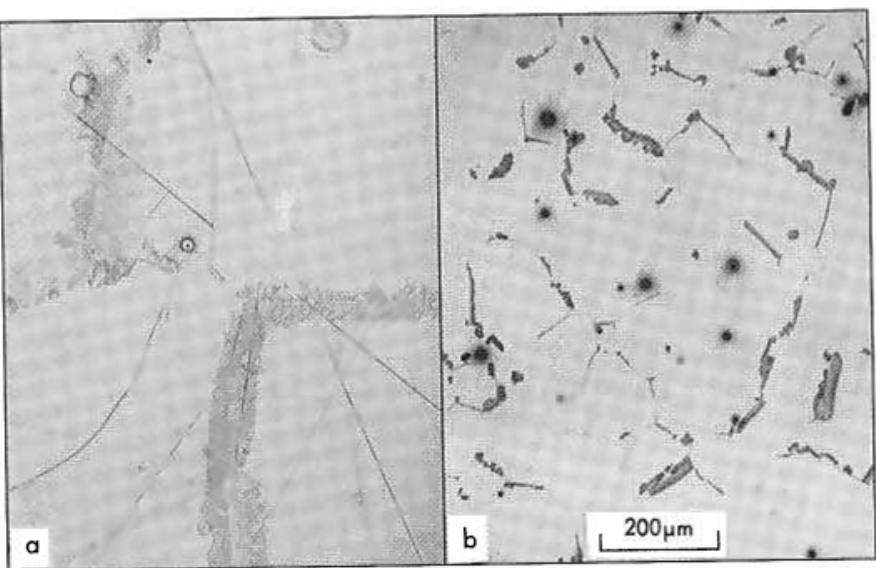

Fig. 8a (left) and 8b (right) Aged microstructures showing precipitation along grain boundaries; (a) Ternary III, and (b) Tiffany

precipitated predominantly along grain boundaries. The microstructural appearance of the alloys generated by casting, homogenization, ordering and aging closely resembles a progression of micrographs published in a study of the age-hardening behavior of a 14 carat gold alloy [29].

Figures $9 a$ and $9 b$ illustrate the fine-grained structure of the alloys produced by rapid solidification. Due to the high cooling rate, grain growth was suppressed. The RSR materials produced were not amorphous; however, casting segregation was less than that found in the alloys produced by the lost-wax method.

Comparison of Figures $3 \mathrm{~b}$ and $9 \mathrm{~b}$ shows that a much finer dispersion of the dark-etching, copper-rich, phase in the Tiffany alloy was produced by the RSR processing. Note also that grain size was reduced from a value of approximately $0.5 \mathrm{~mm}$ to $0.01 \mathrm{~mm}$.

\section{Table III}

Vickers Microhardness for Various Heat Treatments

\begin{tabular}{lrrrr}
\hline Alloy & As-Cast & Homogen. & Ordered & Aged \\
\hline Ternary I & 47 & 47 & 46 & 58 \\
Ternary III & 89 & 86 & 166 & 215 \\
Ternary V & 191 & 178 & 228 & 170 \\
Miracast & 223 & 176 & 270 & 250 \\
Sunrise & 174 & 156 & 285 & 275 \\
Tiffany & 255 & 226 & 282 & 336 \\
Average & 163 & 145 & 213 & 218 \\
& & & & \\
\end{tabular}

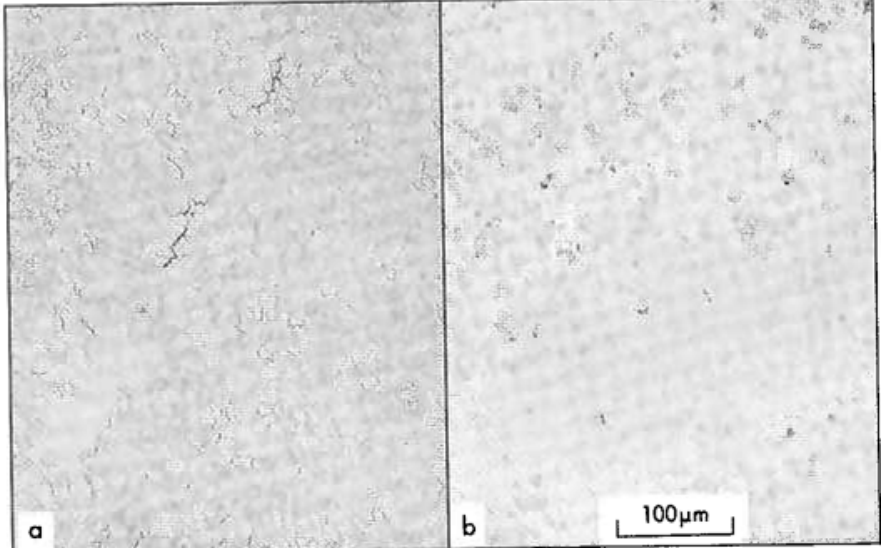

Fig. 9a (left) and 9b (right) Examples of the fine-grained microstructures for the rapidly quenched alloys; (a) Ternary II, and (b) Tiffany

\section{Hardness}

Table III lists the average Vickers microhardness numbers for the alloys in the various thermal states. The column average is also given as an aid in assessing the effects of each of the heat treatments. There is little difference between the as-cast and homogenized hardness values, though some softening occurred after the solidsolution anneal. This is due to grain growth and the elimination of precipitates along the grain boundaries. The hardness of Ternary I remained uniform throughout the thermal processing steps. This material contains only gold and silver, and is single phase; therefore the only hardening contribution will be from solid-solution strengthening, which is not significantly affected by thermal aging.

All of the other test materials showed significant (2590 per cent) hardness increases after the ordering heat treatment. As described earlier, the ordered $\mathrm{AuCu}$ platelets are coherent within the matrix. The coherency strain induced by the formation of the b.c.t. superlattice is an additional hardening mechanism. Hardness increases have also been found after ordering heat treatments in other agehardening studies of low-gold materials [29-31].

After aging for 40 hours at $350^{\circ} \mathrm{C}$, the Ternary III and Tiffany alloys showed a further increase in hardness. The other alloys showed signs of over-aging. Leinfelder, et al. [30] have reported that the maximum hardness of pure gold-copper specimens on ordering occurred at 75 per cent of full order, which was reached after only 20 minutes at $350^{\circ} \mathrm{C}$. Thus, the decrease in hardness may be associated with the attainment of more than 75 per cent full ordering during the 40-hour aging treatment. The addition of silver and other alloying ingredients was found to lower the rate of the ordering reaction. The hardening of the Ternary III and Tiffany alloys can be attributed to the subsequent for- 


\begin{tabular}{|c|c|c|c|c|}
\hline \multicolumn{5}{|c|}{$\begin{array}{c}\text { Table IV } \\
\text { Color Change Vector }\left(\Delta \mathrm{E}^{\star}\right) \text { for All Heat Treatments } \\
\text { (Samples were Tarnished for } 3 \text { Days in } 0.5 \% \text { Sodium Sulfide) }\end{array}$} \\
\hline Alloy & As-Cast & Homog. & Ordered & Aged \\
\hline Ternary I & 57 & 14 & 26 & 42 \\
\hline Ternary III & 58 & 21 & 8 & 43 \\
\hline Ternary V & 60 & 21 & 9 & 35 \\
\hline Miracast & 8 & 5 & 4 & 11 \\
\hline Sunrise & 13 & 7 & 5 & 20 \\
\hline Tiffany & 6 & 3 & 5 & 11 \\
\hline Average & 34 & 12 & 10 & 27 \\
\hline
\end{tabular}

\section{Table V}

Color Change Vector $\left(\Delta E^{*}\right)$ for All Heat Treatments

(Samples were Tarnished for 3 Days in Artificial Saliva)

\begin{tabular}{lcrrr}
\hline Alloy & As-Cast & Homog. & Ordered & Aged \\
\hline Ternaryl & 63 & 23 & 24 & 33 \\
Ternary III & 62 & 28 & 12 & 31 \\
Ternary V & 65 & 40 & 14 & 19 \\
Miracast & 10 & 7 & 9 & 7 \\
Sunnise & 16 & 8 & 14 & 8 \\
Tiffany & 10 & 4 & 15 & 6 \\
Average & 38 & 18 & 15 & 18 \\
\hline
\end{tabular}

Fig. 10 Graphical representation of the data from Table IV (above)

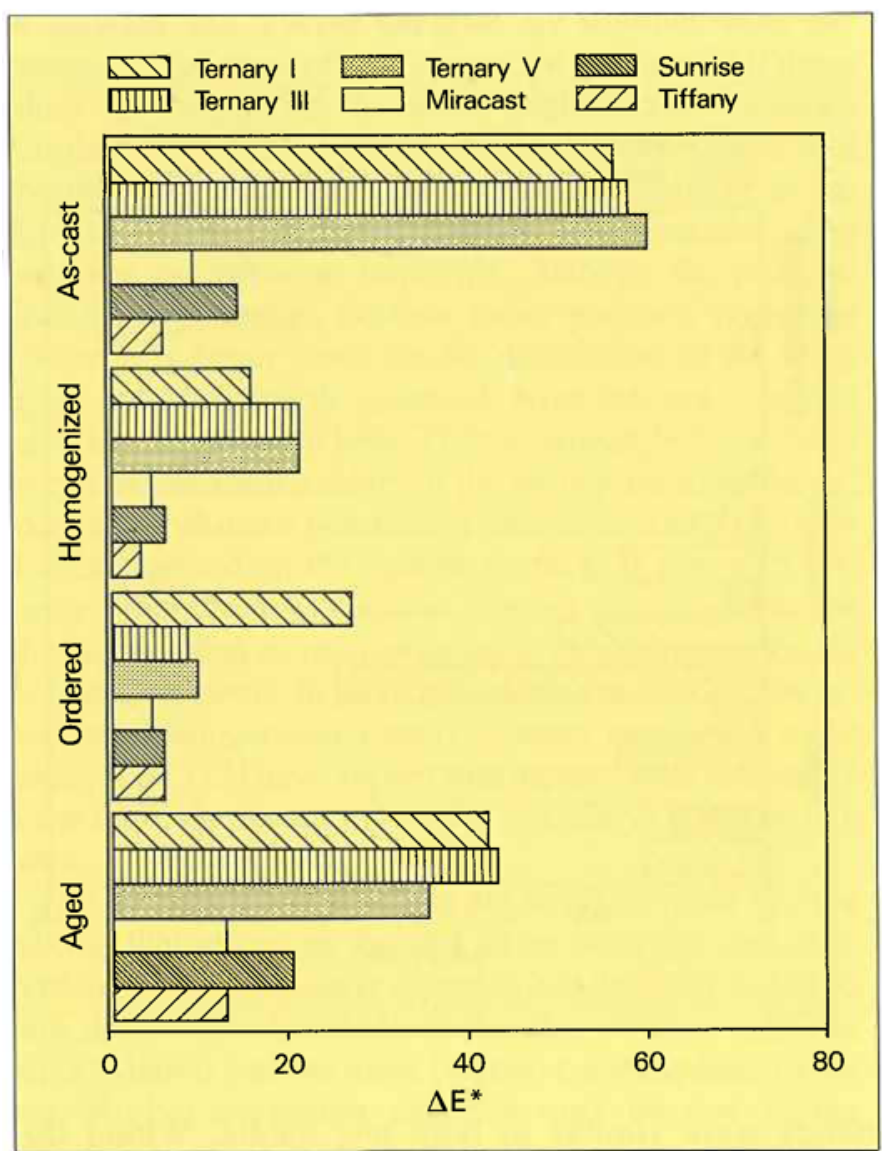

Fig. 11 Graphical representation of the data from Table $V$ (above)

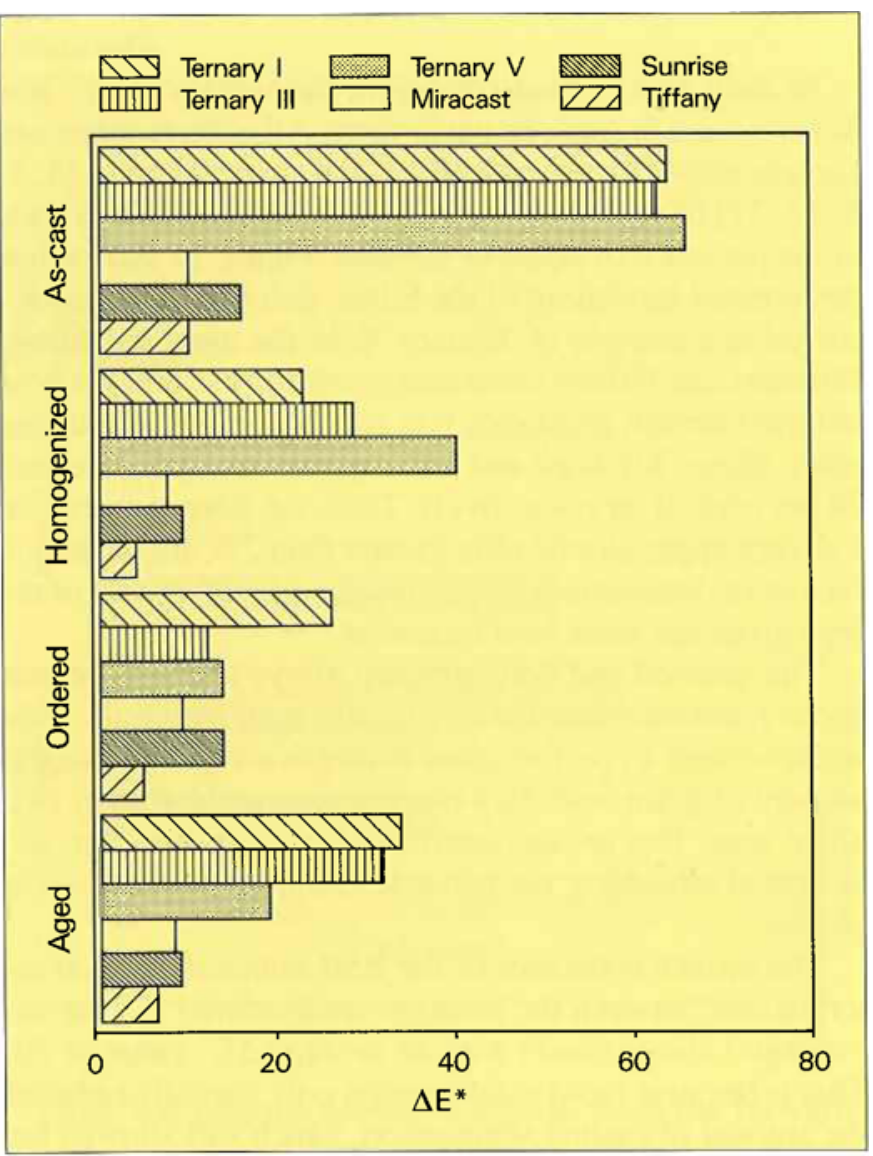

mation of ordered regions which might have previously been suppressed.

\section{Tarnishing}

The mean values of the color change vector $\left(\Delta \mathrm{E}^{*}\right)$ measured after a three-day exposure to 0.5 per cent $\mathrm{Na}_{2} \mathrm{~S}$ and artificial saliva are listed in Tables IV and V respec-

tively (see also Figures 10 and 11). In some instances the data contained rather large standard deviations. These fluctuations were attributed to the tarnish/reflectivity differences of the variously oriented coarse grains, and also to the intermittent trapping and accumulation of tarnish deposits within casting pores. 


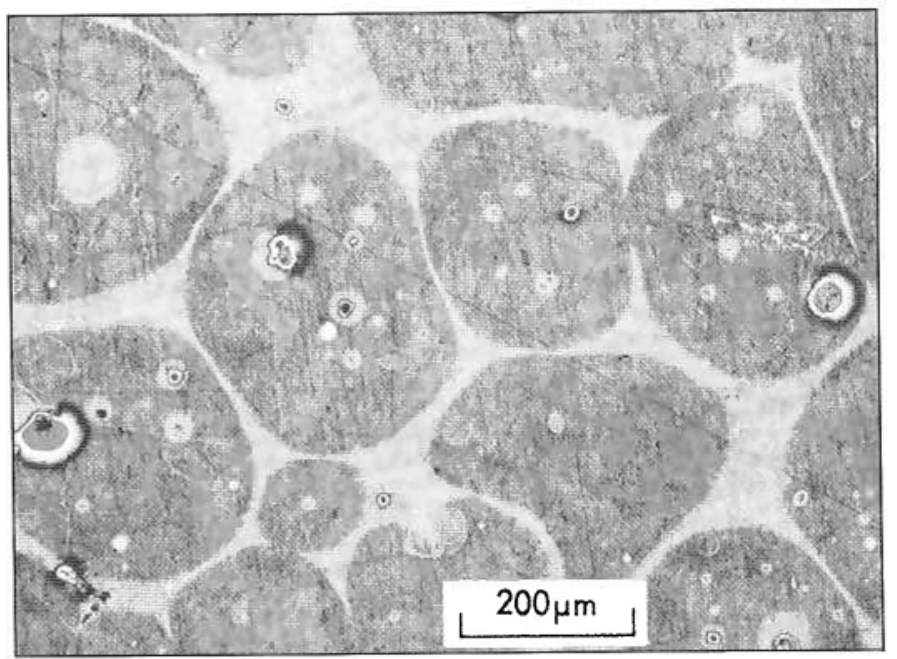

Fig. 12 Preferential tarnish at the silver-rich regions in Ternary $\mathrm{V}$

In each heat-treated condition, the ternary alloys and Sunrise were the poorest performers. All of these materials contain above 45 per cent silver, and several studies [4, 5, $8,12,21]$ have demonstrated that silver readily tarnishes in the presence of aqueous sulfides. Figure 12 shows that preferential tarnishing of the Silver-rich matrix phase occurred in a sample of Ternary V. In the aged condition, Miracast and Tiffany contained second-phase precipitates, but their tarnish resistance was still better than that of the other alloys. Miracast and Tiffany contain 8 per cent and 28 per cent silver respectively. Thus, the silver content, or a silver/copper atomic ratio greater than 2.0 , are the major factors in determining tarnish resistance within a set of alloys given the same heat treatment.

The ordered and homogenized alloys exhibited much better resistance than the as-cast and aged materials. This improvement in performance is due to a reduction of the amount of grain boundary precipitation in the former two alloy sets. Precipitate interfaces provide sites for accelerated tarnishing via galvanic coupling of the discrete phases.

The tarnish resistance of the RSR materials ranked intermediate between the homogenized/ordered and the ascast/aged alloy subsets with an average $\Delta \mathrm{E}^{*}$ value of 20 . This is because rapid solidification only partially reduced the amount of casting segregation, which still allowed for significant tarnish formation via galvanic coupling to occur. The low silver content alloy Tiffany was still the most resistant material in the RSR subset. Thus, rapid solidification does not affect the tarnish characteristics of the elemental silver within these alloys.

The artificial saliva was the more aggressive of the two tarnish solutions used for the tarnishing tests, but data

\begin{tabular}{|c|c|c|c|c|c|c|}
\hline \multicolumn{7}{|c|}{$\begin{array}{c}\text { Table VI } \\
\text { Forward Integral }\left(\mu \mathrm{A}-\mathrm{V} / \mathrm{cm}^{2}\right)\end{array}$} \\
\hline \multirow{2}{*}{$\begin{array}{l}\text { Alloy } \\
\text { Ternary I }\end{array}$} & \multicolumn{2}{|c|}{$\begin{array}{l}\text { As-Cast/Homog. } \\
\text { (NaCl) (Saliva) }\end{array}$} & \multicolumn{2}{|c|}{$\begin{array}{c}\text { Ordered } \\
\text { (NaCl) (Saliva) }\end{array}$} & \multicolumn{2}{|c|}{$\begin{array}{l}\text { Aged } \\
\text { (NaCl)(Saliva) }\end{array}$} \\
\hline & 1 & N.A. & 63 & 48 & 17 & 1174 \\
\hline Ternary III & 7 & N.A. & 50 & 96 & 42 & 135 \\
\hline Ternary V & 20 & N.A. & 97 & 179 & 11 & 397 \\
\hline Miracast & 17 & 32 & 144 & 483 & 686 & 1074 \\
\hline Sunrise & 13 & 4 & 27 & 85 & 150 & 246 \\
\hline Tiffany & 1 & 3 & 31 & 554 & 14 & 309 \\
\hline Average & 10 & 13 & 69 & 241 & 153 & 556 \\
\hline
\end{tabular}

Fig. 13 Graphical representation of the data from Table VI (above) for artificial saliva

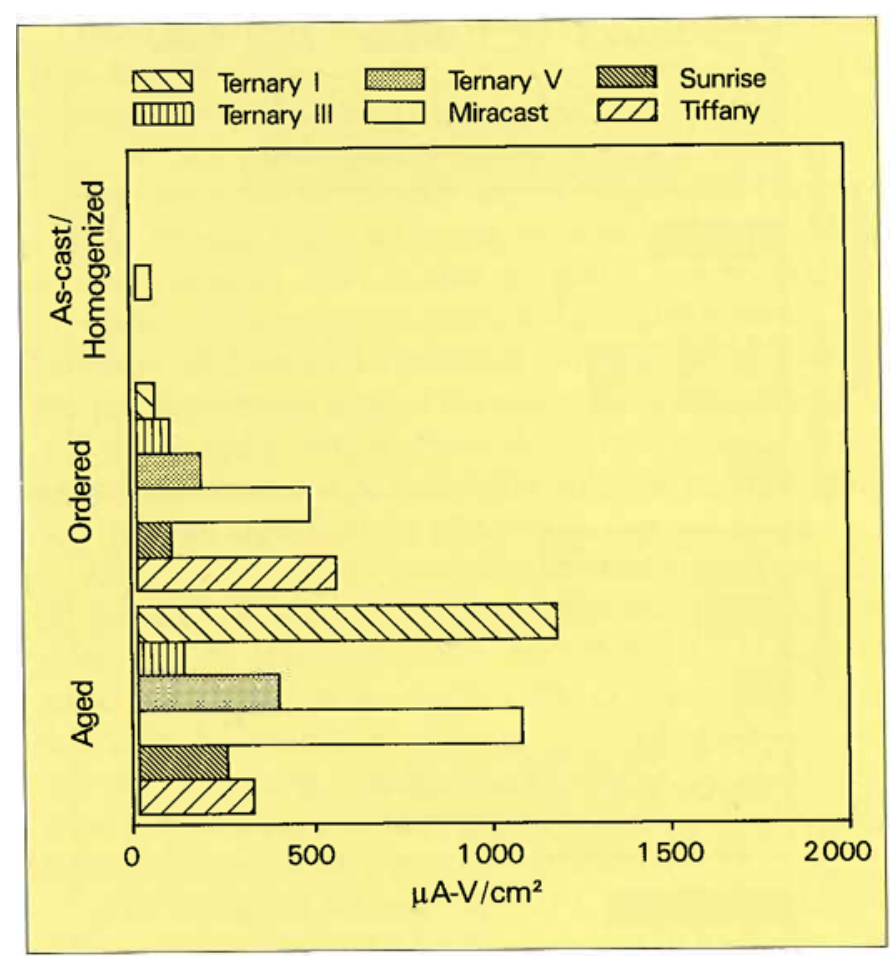

trends were similar in both test media. Within the homogenized and ordered alloy sets, Miracast and Tiffany were the most tarnish resistant. They showed a total color change of approximately 5 , which compares well with the tarnish performance of a Type III certified alloy (B2) for which Treacy and German [4] measured a $\Delta \mathrm{E}^{*}$ value of 3.5. This amount of tarnish is generally not aesthetically displeasing to the patient. 


\section{Corrosion}

There are several potential driving forces for alloy corrosion. These include those arising from electrochemical differences between alloying elements, grain boundary energy, and galvanic coupling in materials containing two or more phases. All three of these mechanisms were observed in the alloy test set; however, the predominance of one over the others was determined by the microstructure and compositional variations induced by thermal processing.

The quantitative corrosion parameters taken from potentiodynamic scans of the alloy set in each heat-treated condition are listed in Tables VI through IX (see also Figures 13,14 and 15). The following general comments can be made on the data from these tables.

Current density is a measure of corrosion rate, and as it increases the alloy corrosion resistance decreases. Both the forward and reverse integrals are summed over the potential range most often observed in the month. If these values are large, this is due to high current densities recorded within those limits, and corrosion rates in the oral environment can be expected to be high. Similarly, as the $(\mathrm{Ag}-\mathrm{Cu}) \mathrm{Cl}$ peak height decreases in magnitude, alloy resistance to corrosion improves. Also, as the rest and breakdown potentials become more positive, corrosion resistance is better since anodic dissolution of the alloy begins at a more noble potential. Note that only the rest potentials are reported here. This parameter better reflects the electrochemical activity of the alloy prior to scanning, since the breakdown potential is measured after a chloride film has formed on the sample surface. It was also discovered that the rest potential is more sensitive than the other parameters to microstructural variations caused by the heat treatments. In all of the tables, the data for the ascast and homogenized materials were combined, since Corso, et al. [22] have shown that there is little difference in the corrosion behavior of the test alloys in these two states.

The forward integral values are listed in Table VI, and indicate that alloys in the as-cast or homogenized state were the most corrosion resistant, while the aged materials were the least resistant. Note that the aereated artificial saliva solution was the more corrosive test medium of the two. Higher corrosion currents may be due to the availability of oxygen to participate in an additional cathodic reaction:

$$
\mathrm{O}_{2}+2 \mathrm{H}_{2} \mathrm{O}+4 \mathrm{e}^{-}=4 \mathrm{OH}^{-}
$$

The standard potential at unit activity for this reaction is $0.16 \mathrm{~V}$ ( $\mathrm{SCE}$ ), which is located within the integration limits.

\begin{tabular}{|c|c|c|c|c|c|}
\hline \multicolumn{6}{|c|}{$\begin{array}{c}\text { Table VII } \\
\text { Reverse Integral }\left(\mu \mathrm{A} \cdot \mathrm{V} / \mathrm{cm}^{2}\right)\end{array}$} \\
\hline Alloy & \multicolumn{2}{|c|}{$\begin{array}{l}\text { As-Cast/Homog. } \\
\text { (NaCl) (Saliva) }\end{array}$} & \multicolumn{2}{|c|}{$\begin{array}{c}\text { Ordered } \\
\text { (NaCl) (Saliva) }\end{array}$} & $\begin{array}{l}\text { Aged } \\
\text { (NaCl) (Saliva) }\end{array}$ \\
\hline Ternary I & 2355 & N.A. & 2400 & 14700 & $39400 \quad 14000$ \\
\hline Ternary III & 2341 & N.A. & 3700 & 1600 & $18800 \quad 14600$ \\
\hline Ternary V & 2263 & N.A. & 9500 & 4100 & $13300 \quad 10300$ \\
\hline Miracast & 1318 & 259 & 2200 & 1400 & $9400 \quad 2900$ \\
\hline Sunrise & 3437 & 2153 & 21600 & 12800 & $22700 \quad 9200$ \\
\hline Tiffany & 2124 & 843 & 4500 & 1900 & $11000 \quad 4200$ \\
\hline Average & 2300 & 1085 & 7300 & 6100 & $19100 \quad 9200$ \\
\hline
\end{tabular}

Fig. 14 Graphical representation of the data from Table VI (above) for artificial saliva

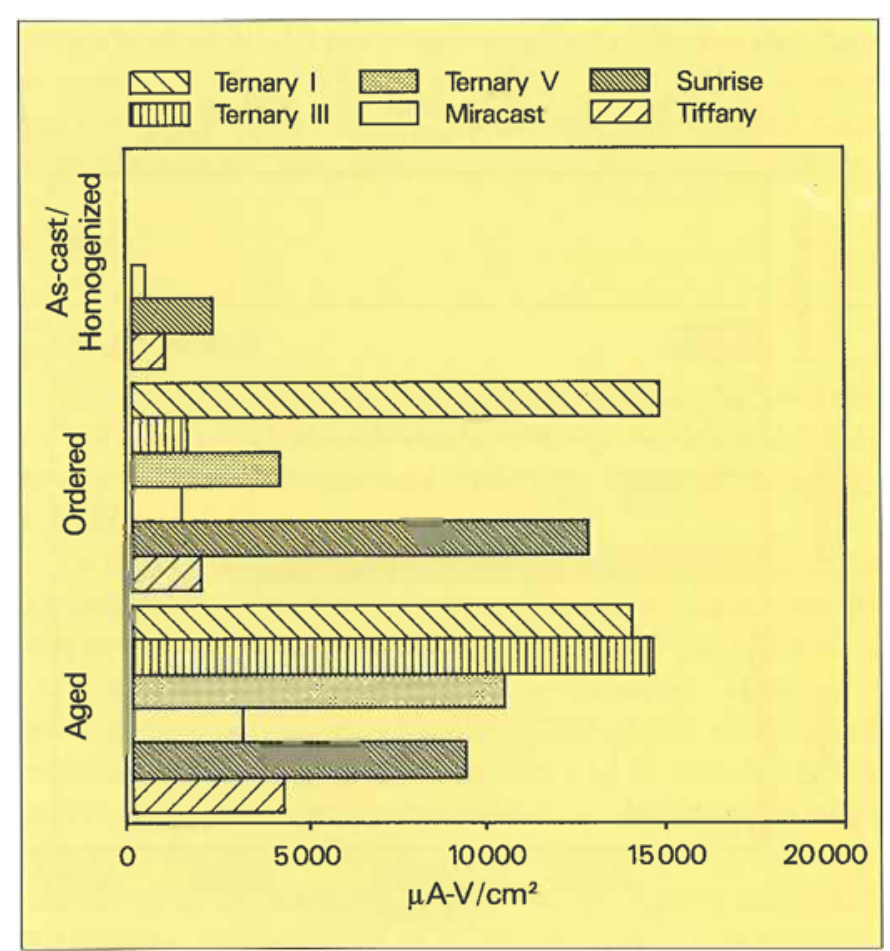

Table VII lists the reverse integrals. Both the forward and reverse integral data are given to validate the trends shown in each category. Again, the corrosion resistance, from best to worst, was as follows: as-cast/homogenized, ordered, aged. However, the artificial saliva was not as aggressive as the saline solution during the cathodic scan. Corso, et al. [22] attributed this trend to the presence of dissolved oxygen in the saliva. 


\begin{tabular}{|c|c|c|c|c|c|c|}
\hline \multirow{3}{*}{$\begin{array}{l}\text { Alloy } \\
\text { Ternary! }\end{array}$} & \multicolumn{6}{|c|}{$\begin{array}{c}\text { Table VIII } \\
(\mathrm{Ag}+\mathrm{Cu}) \mathrm{Cl} \text { Peak Height }\left(\mu \mathrm{A} / \mathrm{cm}^{2}\right)\end{array}$} \\
\hline & \multicolumn{2}{|c|}{$\begin{array}{l}\text { As-Cast/Homog. } \\
\text { (NaCl) (Saliva) }\end{array}$} & \multicolumn{2}{|c|}{$\begin{array}{l}\text { Ordered } \\
\text { (NaCl) (Saliva) }\end{array}$} & \multicolumn{2}{|c|}{$\begin{array}{l}\text { Aged } \\
\text { (NaCl)(Saliva) }\end{array}$} \\
\hline & 20500 & N.A. & 17000 & 60000 & 2500 & 600 \\
\hline Ternary III & 19000 & N.A. & 15000 & 6000 & 3500 & 2000 \\
\hline Ternary V & 21000 & N.A. & 150000 & 15000 & 1100 & 400 \\
\hline Miracast & 8300 & 2100 & 13000 & 4400 & 6000 & 600 \\
\hline Sunrise & 30000 & 10000 & 105000 & 60000 & 13000 & 400 \\
\hline Tiffany & 17000 & 5000 & 35000 & 7000 & 5000 & 1000 \\
\hline Average & 19300 & 5700 & 55800 & 25400 & 5200 & 800 \\
\hline
\end{tabular}

Fig. 15 Graphical representation of the data from Table VIII (above) for artificial saliva

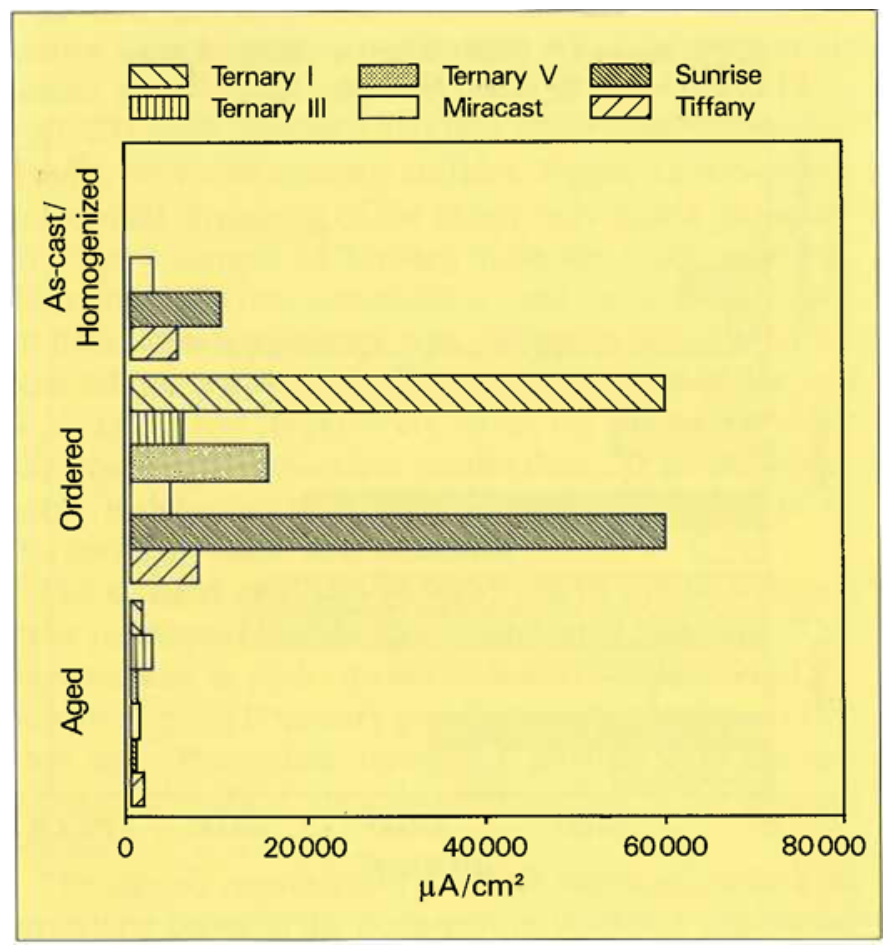

The $(\mathrm{Ag}+\mathrm{Cu}) \mathrm{Cl}$ peak heights are given in Table VIII. The data suggest that the aged alloys are the most resistant to chloride formation. However, these peaks represent only the maximum current density values and do not accurately reflect the shape of the reverse scan curve. The curves generated for the aged materials were very broad, indicating chloride formation over a wide potential range. Conversely, curves for the as-cast/homogenized and ordered alloys were narrowly spiked. Thus, it is obvious that

\begin{tabular}{|c|c|c|c|c|c|c|}
\hline \multicolumn{7}{|c|}{$\begin{array}{c}\text { Table IX } \\
\text { Rest Potential (V, SCE) }\end{array}$} \\
\hline \multirow{2}{*}{$\begin{array}{l}\text { Alloy } \\
\text { Ternary I }\end{array}$} & \multicolumn{2}{|c|}{$\begin{array}{l}\text { As-Cast/Homog. } \\
\text { (NaCl) (Saliva) }\end{array}$} & \multicolumn{2}{|c|}{$\begin{array}{c}\text { Ordered } \\
\text { (NaCl) (Saliva) }\end{array}$} & \multicolumn{2}{|c|}{$\begin{array}{l}\text { Aged } \\
\text { (NaCl)(Saliva) }\end{array}$} \\
\hline & $=0.12$ & N.A. & 0.13 & -0.08 & 0.18 & .0 .20 \\
\hline Ternary III & -0.15 & N.A. & -0.10 & -0.12 & -0.22 & .0 .24 \\
\hline Ternary V & -0.22 & N.A. & .0 .19 & 0.05 & -0.22 & -0.22 \\
\hline Miracast & 0.32 & 0.15 & .0 .08 & -0.34 & -0.33 & -0.26 \\
\hline Sunrise & $=0.30$ & 0.00 & -0.11 & -0.07 & -0.36 & 0.20 \\
\hline Tiffany & -0.22 & 0.00 & $\cdot 0.11$ & -0.13 & .0 .20 & -0.15 \\
\hline Average & -0.22 & +0.05 & -0.12 & .0 .13 & -0.25 & -0.21 \\
\hline
\end{tabular}

a single corrosion parameter does not provide an adequate assessment of an alloy's corrosion performance.

Table IX lists the rest potentials. All of the data fall within the narrow range for -0.36 to $+0.15 \mathrm{~V}$ (SCE) which is expected, since the noble metal content of the test alloys is approximately the same. However, in $\mathrm{NaCl}$ the ordered materials, and in artificial saliva the homogenized materials, exhibited the most noble rest potentials, indicating that the presence of the second phase lowers corrosion resistance. This behavior is typical of the better corrosion resistance afforded by single-phase alloys when compared with dual-phase alloys having the same elemental components.

As mentioned previously, the measurement of a single corrosion parameter does not provide an adequate assessment of the corrosion resistance of a particular material. However, examination of Tables VI through IX shows that the as-cast and homogenized alloys provided the most consistent corrosion resistance. Even though the as-cast materials are dual phase, the potential difference between the copper-rich grain boundary phase and the silver-rich matrix phase is not large. This is because the gold content is approximately the same in each constituent and there is little electrochemical difference between copper and silver. Thus, the contribution of galvanic coupling to corrosion was not significant. The single-phase homgenized alloys performed as well as those in the as-cast condition. None of the three main dirving forces for corrosion (grain boundary energy, galvanic coupling, electrochemical differences) were enhanced by the homgenization heat treatment.

However, ordering is detrimental to corrosion resistance. The ordered Au-Cu platelets have a higher enthalpy than unordered regions of similar composition in the 


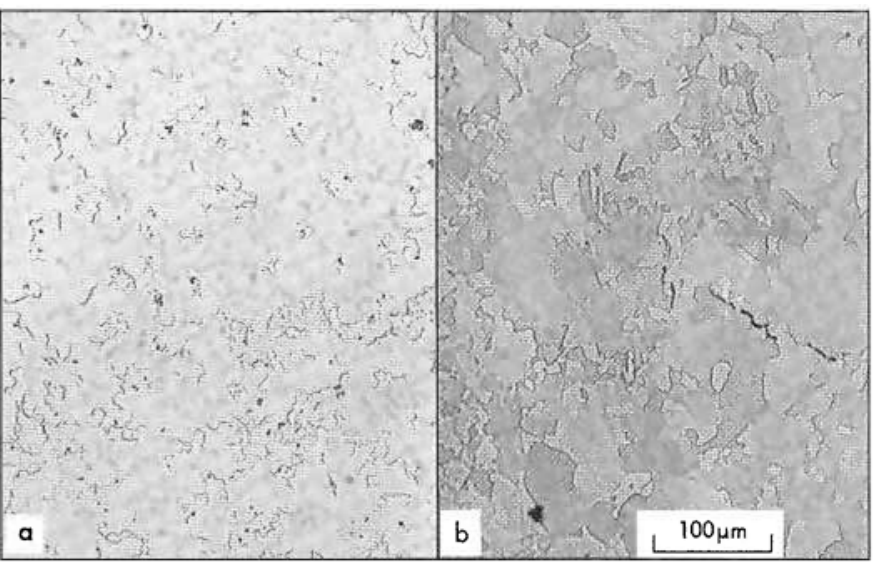

Fig. 16a (left) and 16b (right) The microstructure of Ternary IV; (a) following rapid solidification, and (b) after annealing to promote grain growth

as-cast/homogenized materials. Thus, $\mathrm{Au}-\mathrm{Cu}$ bonding is stronger in the ordered alloys. Dissolution of silver should increase due to microgalvanic coupling with the ordered platelets. This phenomenon is clearly reflected in the chloride peak height data given in Table VII.

Aging also lowers alloy corrosion resistance. This is due to the reprecipitation and subsequent galvanic coupling of the grain boundary phase with the matrix. Note also that in every other heat-treated condition the dual phase alloys (i.e., Ternary V and Sunrise) exhibited the lowest corrosion resistance. Thus, the aged materials were not as resistant as the as-cast, homogenized and ordered materials.

The materials processed by rapid solidification had the poorest overall corrosion performance. In addition to containing casting segregation, they had a very small grain size. Thus, the contribution to the corrosion rate from grain boundary energy was significant. In order to estimate the effect of grain size on the corrosion rate of the RSR materials, two alloys, (Ternary IV, Sunrise) were annealed at $705^{\circ} \mathrm{C}$ for 4 hours to induce grain growth. Figures 16 and 17 show that the grain size was increased about 2.5 times by the anneal. Below is a comparison of two corrosion parameters measured in 1 per cent $\mathrm{NaCl}$ before and after the annealing heat treatment.

$\begin{array}{lcr}\text { Alloy } & \begin{array}{c}(\mathbf{A g}+\mathbf{C u}) \mathbf{C l} \text { peak } \\ \text { height }\end{array} & \begin{array}{r}\text { Reverse } \\ \text { integral }\end{array} \\ \text { Ternary IV } & 150000 & 23000 \\ \text { Ternary IV (annealed) } & 105000 & 9900 \\ \text { Sunrise } & 275000 & 32000 \\ \text { Sunrise (annealed) } & 200000 & 23000\end{array}$

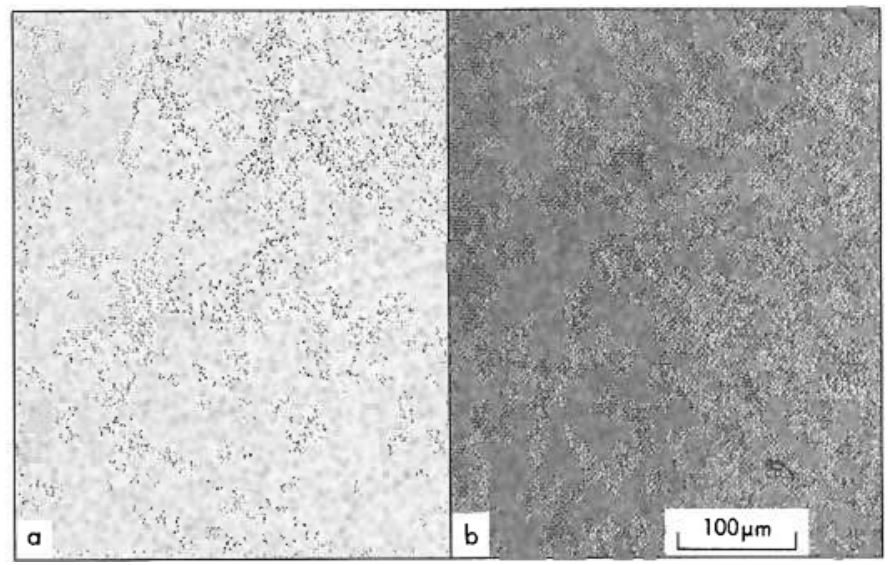

Fig. 17a (left) and 17b (right) The microstructure of Sunrise; (a) following rapid solidification, and (b) after annealing to promote grain growth

These results indicate that a corrosion performance improvement of 30-50 per cent was effected by the increase in grain size of the RSR alloys. Thus, the relatively large grain sizes of the materials in the other heat-treated conditions aid in keeping their corrosion rates to a minimum.

\section{Conclusions}

Comparison of the tarnish and corrosion data allows the following overall performance ranking of the heat treatments: $1_{\mathrm{f}}$ homogenization; 2 . ordering, 3 . as-cast, 4 . aging, 5. RSR.

Of the eight alloys tested, Miracast (in the homogenized condition) was the most resistant. There was a wide variation in the tarnish and corrosion behavior of the test alloys as microstructural changes were induced. However, microstructural inhomogeneities (dual-phase alloys) and extremes (very small grain sizes) should be avoided when seeking the most resistant materials. Homogenization provided the most resilient microstructure, and this heat treatment is an economical method of significantly improving the performance of as-cast low-gold restorations; hence this procedure is recommended by commercial dental casting alloy producers.

Dental casting shops can install a furnace system for less than US $\$ 2000$. Material cast during the day could be homogenized at $800^{\circ} \mathrm{C}$ overnight in the furnace under an argon atmosphere. The cost of argon gas supplied in cylinders is not excessive. This practice would be consistent with the trend towards improved quality and longer lived products in the present-day manufacturing community. 


\section{Abstract}

Three commercial 'low'-gold dental casting alloys (25 per cent gold) and five gold-silver-copper ternary alloys (with 35 atomic per cent gold) were subjected to a variety of heat treatments to produce a range of microstructures for investigation, which included those in the as-cast condition, after rapid solidification from the melt, and after aging following solutionization. The corresponding variations in microstructure were noted and measurements were taken of both the tarnish and corrosion responses. It was found that resistance to chemical attack increased with microstructural homogenization; the desirable features of low gold content alloys are large grains, a minimum of segregation, and the absence of precipitates and ordered phases.

\section{Acknowledgements}

This study was performed in the Materials Research Center at RPI using equipment and research funds from the National Institute for Dental Research and International Gold Corporation. The authors are appreciative of the help and advice provided by Julie Gold and Carrie Ekstrand during this study.

\section{References}

1 L.W. Laub and J.W. Stanford, Gold Bull., 1981, 14, 13-18

2 R.M. German, Inter. Metals Revs., 1982, 27, 260-288

3 D.L. Johnson, V.W. Rinne and L.L. Bleich, J. Dent. Res. 1983, 62, 1221:1225

4 D.J.L. Treacy and R.M. German, Gold Bull., 1984, 17, 46-54

5 D.C. Wright, R.F. Gallant and L. Spanberg, J. Biomed. Mater. Res., 1982, 16, 509-517

6 J. Brugirard, R. Bargain, J.C. Dupuy, M. Mazille and G. Monnier, J. Dent. Res., 1973, 52, 828-836

7 A.B. Burse, M.L. Swartz, R.W. Phillips and R.W. Dykema, J. Biomed. Mater. Res., 1972, 6, 267-277

8 R.M. German, Metallog., 1981, 14, 253-266

9 R.M. German, D.C. Wright and R.F. Gallant, J. Prosth. Dent., 1982, 47, 399-406

10 L. Gettleman, F.H. Cocks, L.A. Darmiento, P.A. Levine, S. Wright and D. Nathanson, J. Dent. Res., 1980, 59, 689-707
11 H. Hero, J. Dent. Res., 1984, 63, 926-931

12 H. Hero and R.B. Jorgensen, J. Dent. Res., 1983, 62, 371-376

13 B.R. Lang, S.H. Berivier, Z. Giday and K. Asgar, J. Prosth Dent., 1982, 48, 245-252

14 R.P. Lubovich, R.E. Kovarik and D.L. Kinser, J. Prosth Dent., 1979, 42, 534-538

15 N.K. Sarkar, R.A. Fays and J.W. Stanford, J. Dent. Res., $1979, \mathbf{5 8}, 568-575$

16 J.J. Tuccillo and J.P. Nielsen, J. Prosth. Dent., 1971, 25, 629-637

17 T.K. Vaidyanathan and A. Prasad, J.Biomed. Mater. Res., $1981,15,191-201$

18 H. Hero and J. Valderhang, J. Dent. Res., 1985, 64, $139-143$

19 L. Niemi and H. Hero, J. Dent. Res., 1985, 64, 1163-1169

20 D.C. Wright, R. Gallant and L. Spangberg, Precious Metals 1981, E.D. Zysk (ed.), Pergamon Press, Toronto, 1982, 433-441

21 P.P. Corso, Jr., R.M. German and H.D. Simmons, Jr., J. Dent. Res., 1985, 64, 848-853

22 P.P. Corso, Jr., R.M. German and H.D. Simmons, Jr., J. Dent. Res., 1985, 64, 854-859

23 K.J. Fioravanti, 'The Effect of Heat Treatment on the Chemical Stability of Low-Gold Dental Alloys', M.S. Thesis, Rensselaer Polytechnic Institute, Troy, N.Y., May 1985

24 L.A. O'Brien, 'In Vitro Tarnish and Corrosion Behavior of Pd-Ag Dental Casting Alloys", M.S. Thesis, Rensselaer Polytechnic Institute, Troy, N.Y., August 1984

25 A. Prasad, T. Eng and K. Mukherjee, Mater. Sci. Eng., $1976,24,179-185$

26 H. Hero, R. Jorgensen and E. Sorbroden, J. Dent. Res., $1982,61,371.376$

27 K. Yasuda and Y. Kanzawa, Japan Inst. Met., 1977, 18, 46-54

28 Y. Kanzawa, K. Yasuda and H. Metahi, J. Less-Common Met., 1975, 43, 121-128

29 M. Pickus and I. Pickus, Metals Tech., 1943, 10(3), Tech. Pub. 1555, 1-7

30 K. Leinfelder, W. O'Brien and D. Taylor, J. Dent. Res., 1972, 51, 900-905

31 V. Arunachalam and R. Cahn, J. Mater. Sci., 1967, 2, $160-170$

32 A. Giogia, P. Rao and J. Sekhar, J. Mater. Sci., 1985, 20, 3091-3100

33 S. Hwang, R. Laforce, A. Ritter and R. Goehner, Metall. Trans. A., 1985, 16A, 1773-1779 